\title{
Constitutive analysis of the mechanical anisotropy of Opalinus Clay
}

\author{
Simon Salager $\cdot$ Bertrand François $\cdot$ \\ Mathieu Nuth • Lyesse Laloui
}

Received: 7 December 2011/ Accepted: 22 August 2012

(C) Springer-Verlag 2012

\begin{abstract}
This paper aims to analyse the anisotropic features of behaviour of Opalinus Clay using the theory of plastic multi-mechanisms. The results of triaxial tests conducted with different load levels and directions showed that the mechanical behaviour of this shale is cross-anisotropic. The stiffer samples are those in which the loading direction is parallel to the bedding plane. This indicates that the preconsolidation stress depends on the orientation of the load with respect to the fabric of Opalinus Clay. It is proposed to interpret the observed cross-anisotropy with an elastoplastic model based on four plastic strain mechanisms that may be successively mobilised depending on the loading direction. The predicted stress-strain responses vary according to the directions of the space as a result of the hardening process, depending on the number of plastic strain mechanisms that have been mobilised. The numerical predictions show overall good agreement with the
\end{abstract}

\section{S. Salager $(\square)$}

Grenoble-INP, UJF-Grenoble 1, CNRS UMR 5521, 3SR Lab, 38041 Grenoble, France

e-mail: simon.salager@hmg.inpg.fr

\section{B. François}

Department of Civil Engineering, Université de Sherbrooke, 2500 Boul. Université, Sherbrooke, QC J1K 2R1, Canada

e-mail: mathieu.nuth@usherbrooke.ca

\section{Nuth}

Laboratoire de GéoMécanique, Building, Architecture and Town Planning Department (BATir), Université Libre de Bruxelles, Avenue F.D. Roosevelt, 50-CPI 194/2, 1050 Brussels, Belgium e-mail: bertrand.francois@ulb.ac.be

\section{Laloui}

Laboratory of Soil Mechanics, Ecole Polytechnique Fédérale de Lausanne, Station 18, 1015 Lausanne, Switzerland

e-mail: 1yesse.laloui@epfl.ch experimental data in terms of deviatoric stress versus axial strain, demonstrating that multi-mechanism plasticity is a suitable constitutive tool for the interpretation of the mechanical anisotropy of this shale.

Keywords Cross-anisotropy · Opalinus Clay · Plasticity · Shale mechanical behaviour - Triaxial tests

\section{Introduction}

Anisotropy is an important characteristic influencing the behaviour of shales. The properties of shales usually depend on the direction in which they are measured. The directionality of mechanical behaviour (among other aspects, such as hydraulic, thermal, electric or magnetic processes) occurs as a result of micro- and macro-structural factors. First, singular directions are defined at the microscale during the process of rock formation (deposition, compaction and diagenesis) through the fabric, the texture, the crystallography or the grain arrangements [14, 32, 37]. Second, at a larger scale, bedding, schistosity, cleavage or foliation also affect the anisotropic character of shales. In addition, induced anisotropic behaviour may be the result of the application of anisotropic stress changes developing preferential orientations of elongated void particles $[24,38]$, fractures, shear planes and faults or joints [11]. In both cases (intrinsic or induced anisotropy), hydrostatic (isotropic) loadings may reduce the anisotropic nature of the material. The main concern of this paper is to consider the anisotropy as a consequence of the geomechanical history of the material. So doing, no distinction is made between intrinsic and induced anisotropy. In other words, the intrinsic anisotropy is addressed as an anisotropy induced during the formation (deposition and compaction) 
of the rock upon an anisotropic stress state. This makes sense if the effect of diagenesis and cementation (or any other chemical transformation) on the rock anisotropy is neglected.

The interpretations of the anisotropic character of the mechanical behaviour of shales are, in most cases, limited to the sensibility of elastic properties on loading orientation $[11,14,17]$ and eventually to the failure criteria $[6,13,20$, 22, 23, 26, 33, 34]. Duveau et al. [5] reviewed the main failure criteria dedicated to strongly anisotropic rocks. However, in many geotechnical applications, the combination of an elastic model with a failure criterion for anisotropic rock is not enough to analyse a large-scale behaviour of geostructures. A complete description of the material stress-strain response including hardening and softening is required. Therefore, advanced constitutive models dedicated to anisotropic materials were developed and employed [i.e. 1, 7, 25].

The material that we are investigating in this study is Opalinus Clay of northern Switzerland. From a quantitative laboratory analysis of core samples from Benken and Mont Terri, a total mass fraction of clay minerals of 54-66\%, a quartz content of $14-20 \%$ and $13-16 \%$ calcite were measured [2]. This mineralogical composition exhibits moderate lateral variability and a slight increase in clay content with depth. Due to its high clay content and its fissility, this material has been classified as shale. This material was identified as a potential host rock formation for radioactive waste repositories because of its low permeability and ability to retain radionuclides. Over the last decade, comprehensive geotechnical investigations have been conducted to characterise the geological, hydrogeological and geochemical properties of this geomaterial $[2,19,35]$. The studies indicate that Opalinus Clay exhibits a significant anisotropy in various parameters, such as seismic velocities [27], hydraulic conductivity [21], thermal conductivity $[8,9]$ and coefficient of diffusion of chemical species [30, 36]. However, limited evidence of the mechanical anisotropy of Opalinus Clay has been published $[3,15,29]$. This paper is an attempt to contribute to this area of research. [38] evidenced, from high energy $\mathrm{X}$-Ray tomography, that Opalinus Clay exhibits a strong preferred orientation of its micro-fabric and texture, which is consistent with its geological history (sedimentation, compaction and deformation). Also, the mineral orientation correlates with the anisotropy of the mechanical properties (i.e. acoustic-wave propagation). This preferred grain orientation that defines the shale fabric is attributed to the mechanical rearrangement of particles and the mechanical collapse of the initial high-porosity clay under increasing overburden pressure [16]. Those observations at the micro-scale evidence that the macroscopic mechanical anisotropy is consistent with the micro-fabric properties, this macro-fabric being a consequence of the anisotropic mechanical loading undergone during the formation of the rock. The objective of the proposed model is to reconstruct the mechanically induced anisotropy of the Opalinus Clay from the virgin state through deviatoric mechanical loadings.

The paper is organised as follows. The first part is dedicated to the analysis of experimental results extracted from uniaxial compression tests as well as triaxial compression tests on Opalinus Clay. The test series provide clear evidence of cross-anisotropy in the mechanical behaviour of the material. In the second part, the formulation of an elastoplastic model with four plastic strain mechanisms is presented. The model has been identified as being compliant with induced cross-anisotropy. Given the fact that the constitutive model is highly sensitive to the history and directions of stress, the preloading process is presented. Finally, numerical simulations are compared with selected experimental results, and the plasticityinduced anisotropy of the clay is discussed.

\section{Evidence of the mechanical anisotropy of Opalinus Clay}

The mechanical response of Opalinus Clay has been thoroughly investigated by the Swiss National Cooperative for the Disposal of Radioactive Waste (NAGRA). The experimental results presented in this paper have been extracted from project-specific documents supplied by NAGRA. A selection of 18 uniaxial compression tests and 33 triaxial tests taken from the database are compiled here. Those tests benefit from good data quality, systematic and documented testing procedures and repeated measurements that allow a coherent constitutive interpretation. In the compilation of the triaxial and uniaxial tests, three different orientations of bedding have been considered with respect to the loading direction (Fig. 1):

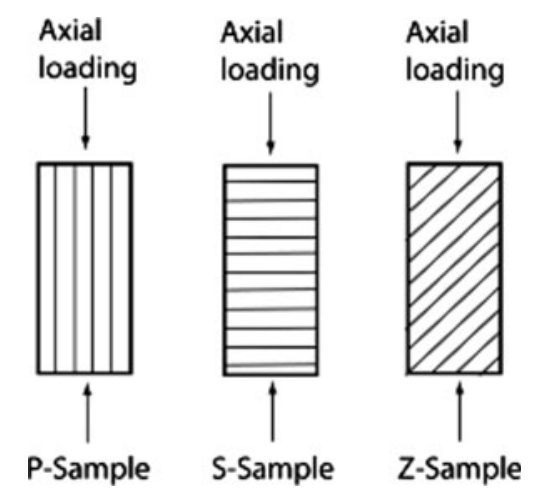

Fig. 1 Orientation of loading direction relative to the bedding in the P-, S- and Z-samples 
- parallel (P-sample)

- perpendicular (S-sample)

- with an inclination of $45^{\circ}$ (Z-sample)

All of the tests were performed on cylindrical samples extracted from boreholes cored in the Mont Terri underground laboratory at a depth of approximately $300 \mathrm{~m}$ (Mont Terri laboratory is a research facility for the hydrogeological, geochemical and geotechnical characterisation of Opalinus Clay formation, near St Ursanne in Switzerland). This corresponds to an in situ pressure of approximately $20 \mathrm{MPa}$.

The followed procedure was similar for each test:

(i) The sample is first loaded to the target hydrostaticconfining pressure $(0,5,10$ or $15 \mathrm{MPa})$.

(ii) A fluid pressure of approximately $0.3 \mathrm{MPa}$ is then applied to the sample from both sides (above and below the cylinder).

(iii) The isotropic consolidation of the sample is made over a period of $24 \mathrm{~h}$.

(iv) The axial load is then increased with a strain rate of $10^{-6} \mathrm{~s}^{-1}$

Twenty-four hours were considered as a sufficient consolidation time to obtain a stable initial state for the shearing process. However, it is noted that because of the relatively fast compression rate used in the consolidation phase, fully drained conditions may not be attained; therefore, only the total stress interpretation is consistent.

Figures 2, 3 and 4 sort the uniaxial and triaxial test results according to the three directions of loading (P-sample, S-sample and Z-sample, respectively). Each test has been duplicated several times using the same experimental conditions, so different symbols have been drawn in the figures to differentiate the individual samples. The same scales and labels of axes were used for each graph (axial strain [0-4\%] and deviatoric stress [0-60 MPa]) to help with the comparison between results.

Results shows, in general, a relatively high spreading. The volumetric strain versus the axial strain representation shows scattered results that can likely be attributed to the conditions of drainage and saturation that are not fully controlled, as mentioned previously. Therefore, within a total stress context, the following interpretation will be mostly based on the stress-strain curves. In the pseudolinear part of the stress-strain curves, the very steep slope accounts for the high rigidity of the shale. The pseudoelastic behaviour is followed by a limited hardening zone (around the peak) that is followed by brittle failure. When the confining pressure increases, the axial strain at failure increases, reaching a maximum of $3.5 \%$ for a confining pressure of $15 \mathrm{MPa}$. Therefore, the brittleness appears to decrease when the confining level increases, which is a well-known feature of the behaviour of most geomaterials [10]. Because of the spreading in the results, the comparison between the results of $\mathrm{P}-, \mathrm{S}$ - and $\mathrm{Z}$-samples is not immediate and it requires an averaging of the different curves to be carefully interpreted (as done in Figs. 5 and 6).

Each set of results may be considered as a scatter plot in the plane of deviatoric stress versus axial strain from which simple trend curves must be extracted for the constitutive interpretation. Conventional statistical tools such as the arithmetic mean could not be used effectively on the results, principally because the shale response is highly nonlinear and varies between tests. For example, for $\mathrm{P}$-samples at the confining pressure of $5 \mathrm{MPa}$ and at the x-ordinate (axial strain) of $1 \%$ (Fig. 2b), some samples have already reached the residual, post-peak stress, whereas others remain in a ductile phase. Therefore, a mathematical averaging of a residual stress and a stress under strain hardening would not be consistent.

We therefore propose to draw a trend curve for each type of test based on a visual interpretation of the results. The trend curve is an attempt to extract average curves with the following features:

- An initial elastic pseudo-linear behaviour

- Strain hardening up to peak resistance

- Brittle failure/post-peak behaviour, if relevant

No fitting parameter was determined, but strong correlations could be expected in each of the 3 zones of behaviour listed above. The results are plotted in Fig. 5, with thin black lines representing the experimental results and thicker grey lines representing the trend curves. The visual trend curves are regarded only as a qualitative tool to compare the P-, S- and Z-sample results and to help with the subsequent calibration of the constitutive model.

Figure 6 compares the typical responses of Opalinus Clay with respect to the orientation of the axial loading by superimposing the grey (averaged) curves as determined in Fig. 5. Figure 6 indicates that the behaviour of the shale is anisotropic:

- P-samples present a higher rigidity than other samples. For example, at a confining pressure of $5 \mathrm{MPa}$, the deviatoric stress reached by the P-sample at $1 \%$ of vertical strain is $32 \mathrm{MPa}$, compared with $12 \mathrm{MPa}$ in the case of the S-sample at the same strain. The trend is the same for all of the confining pressures.

- S-samples exhibit a more ductile behaviour. This aspect is clearly highlighted by the results obtained for confining pressures of 10 and $15 \mathrm{MPa}$ in which S-samples sustained more than $2 \%$ of vertical strain. In addition, contrary to the P-samples, the S-samples are in a continuous hardening process without the occurrence of a peak. 

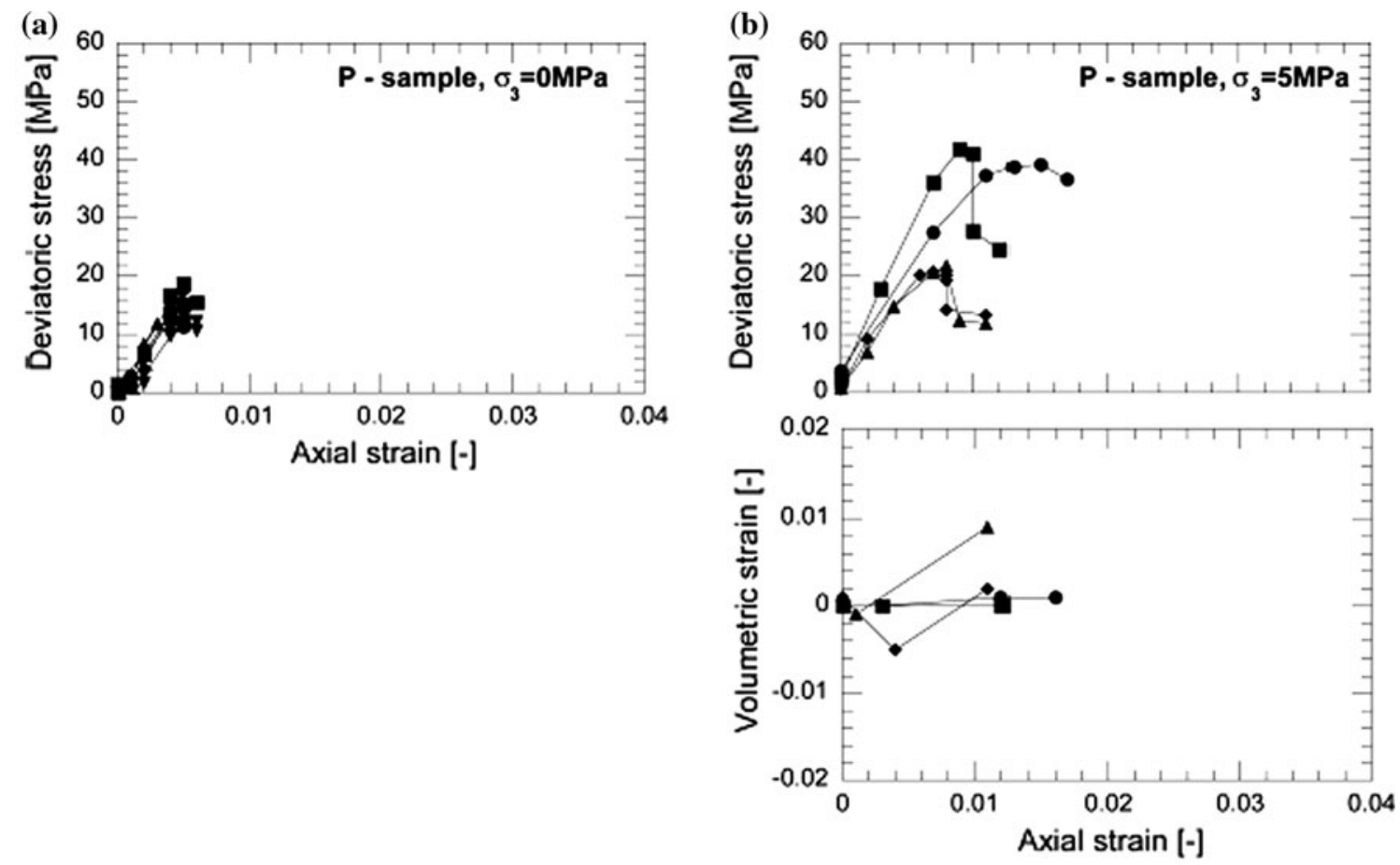

(c)

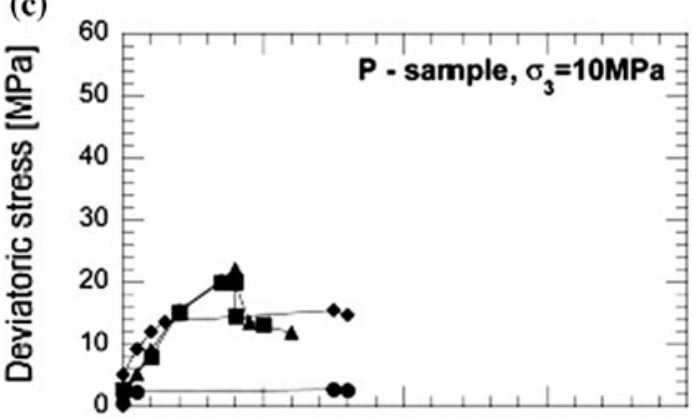

(d)
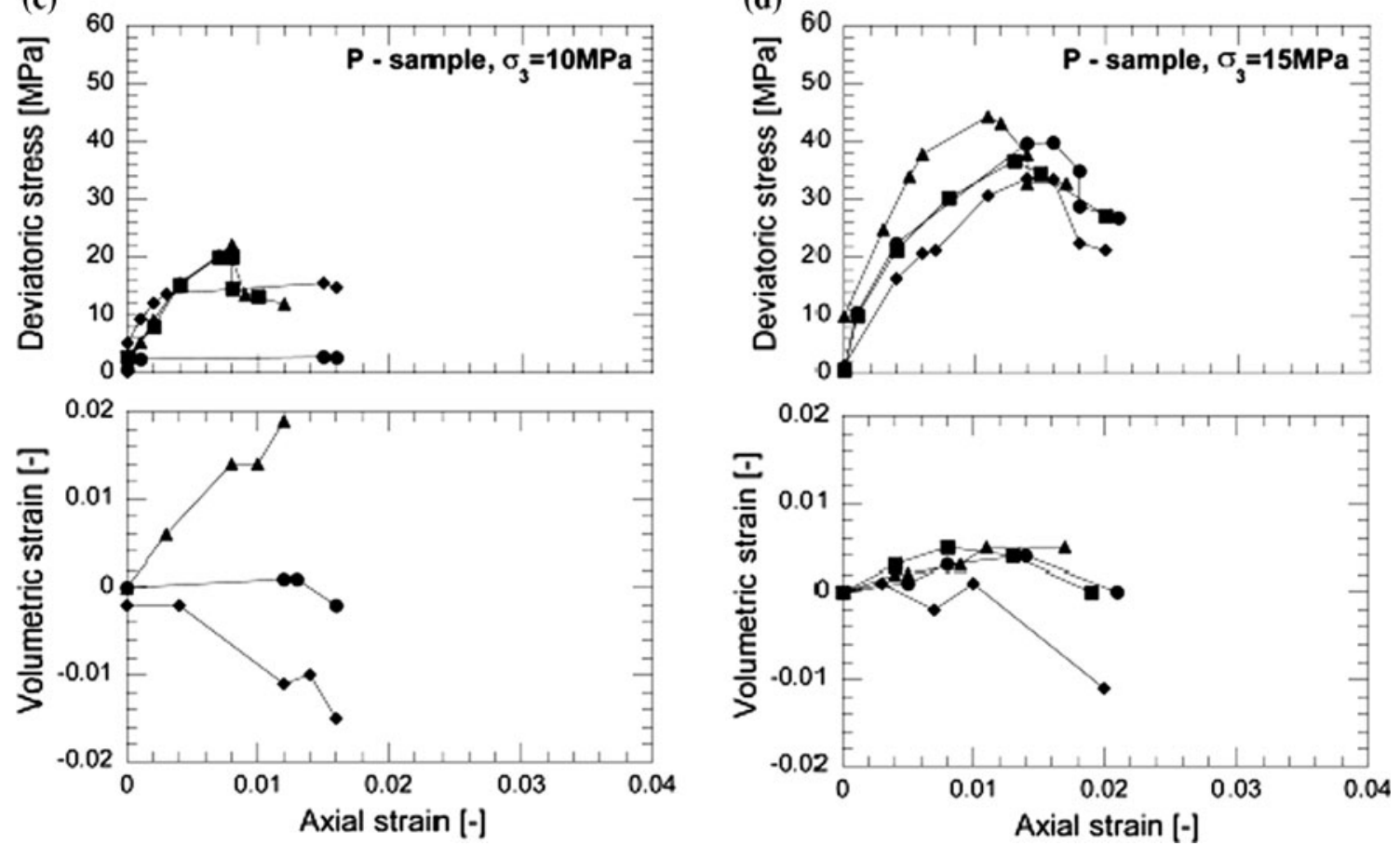

Fig. 2 Compilation of triaxial tests on Opalinus Clay with the axial loading parallel to the bedding orientation (P-samples). The confining pressures are a $0 \mathrm{MPa}$, b $5 \mathrm{MPa}$, c $10 \mathrm{MPa}$ and d $15 \mathrm{MPa}$

- The response of the Z-samples is for a wide range of strain values between the responses of the other samples.

Generally, the behaviour of the P-samples during the triaxial shearing path can be defined first by a quasi-linear relationship between stress and strain, followed by a peak and finally perfect plasticity, which is the typical behaviour of overconsolidated materials. In the case of the S-samples, the quasi-linear part is reduced and followed exclusively by hardening.

Two essential conclusions can be drawn regarding these experimental observations: (1) the behaviour of the Z-samples is between the behaviours of the P-samples and the S-samples, 

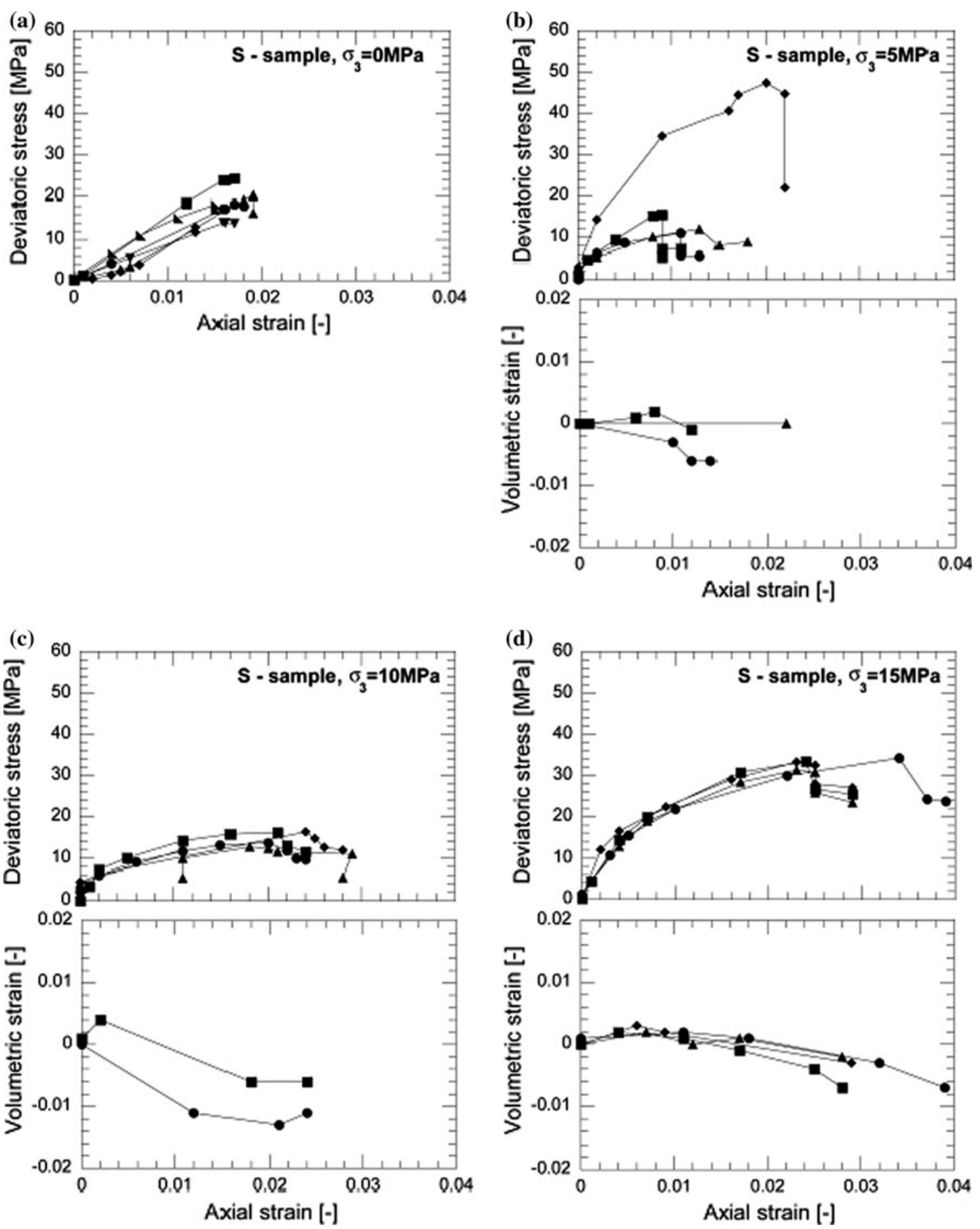

Fig. 3 Compilation of triaxial tests on Opalinus Clay with the axial loading perpendicular to the bedding orientation (S-samples). The confining pressures are a $0 \mathrm{MPa}, \mathbf{b} 5 \mathrm{MPa}, \mathbf{c} 10 \mathrm{MPa}$ and d $15 \mathrm{MPa}$

which is in agreement with anisotropic behaviour, and (2) the stress history induce a typical response on the material that is more overconsolidated for the P-sample than for the S-sample.

Even though the visual averaging only has a qualitative value, it enables us to sort out the experimental results on the basis of the major trends in the rigidity, hardening and orientation of the load with respect to the bedding plane. This qualitative classification of P-, S- and Z-samples will be useful for the calibration of a constitutive model accounting for induced anisotropy. 

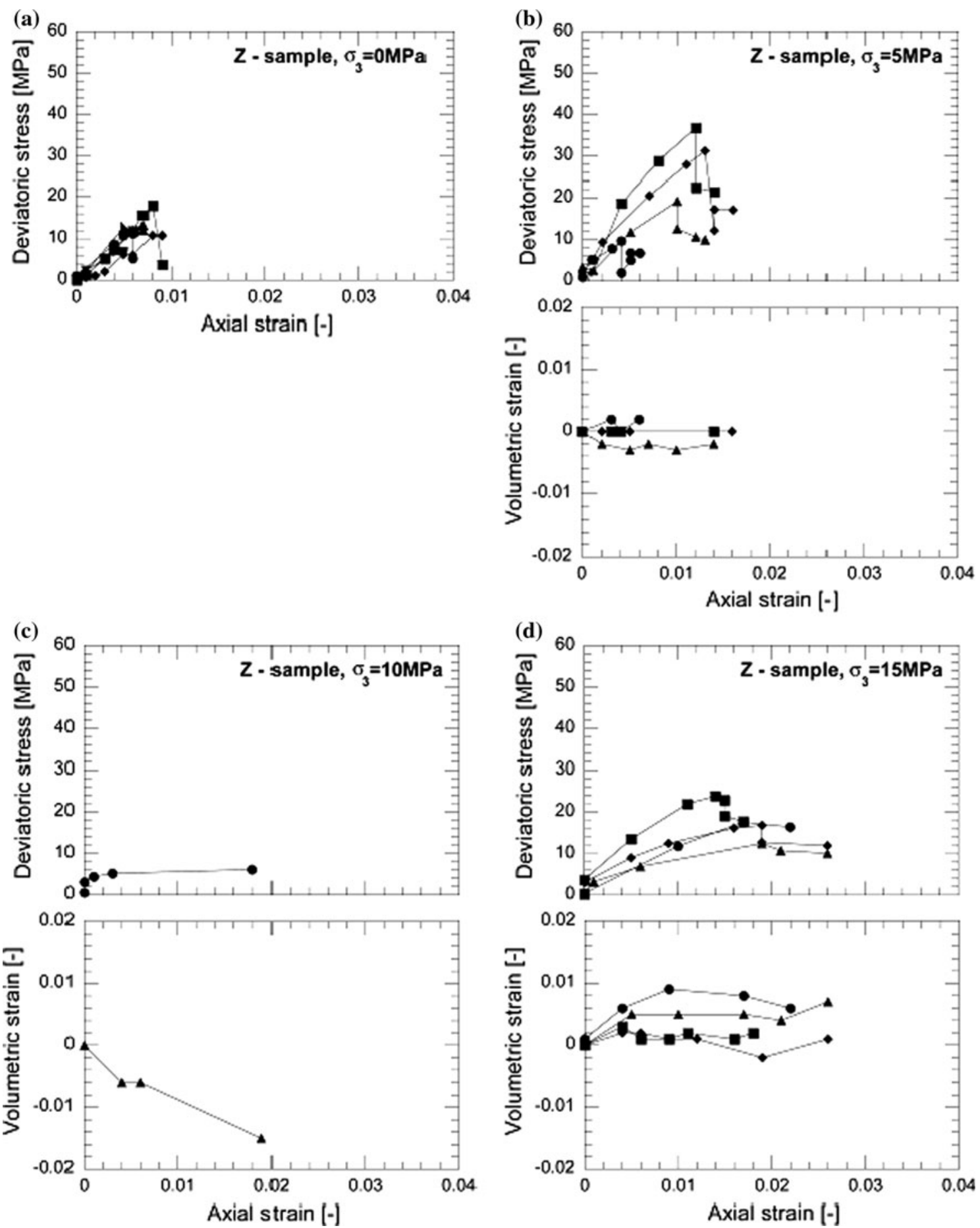

Fig. 4 Compilation of triaxial tests on Opalinus Clay with the axial loading oriented at $45^{\circ}$ relative to the bedding orientation (Z-samples). The confining pressures are a $0 \mathrm{MPa}, \mathbf{b} 5 \mathrm{MPa}$, c $10 \mathrm{MPa}$ and d $15 \mathrm{MPa}$

\section{Anisotropic elastoplastic framework for Opalinus Clay}

In this section, we propose to use Hujeux's constitutive model based on four plastic strain mechanisms [12] to capture the main features of the mechanical behaviour of
Opalinus Clay, and, specifically, its anisotropy. Hujeux's model, which based on a Cam-Clay type critical state model, allows reproducing cyclic behaviour extended towards the consideration of three plastic deviatoric mechanisms associated with the three orthogonal planes of space. In addition, there is a supplementary mechanism of 

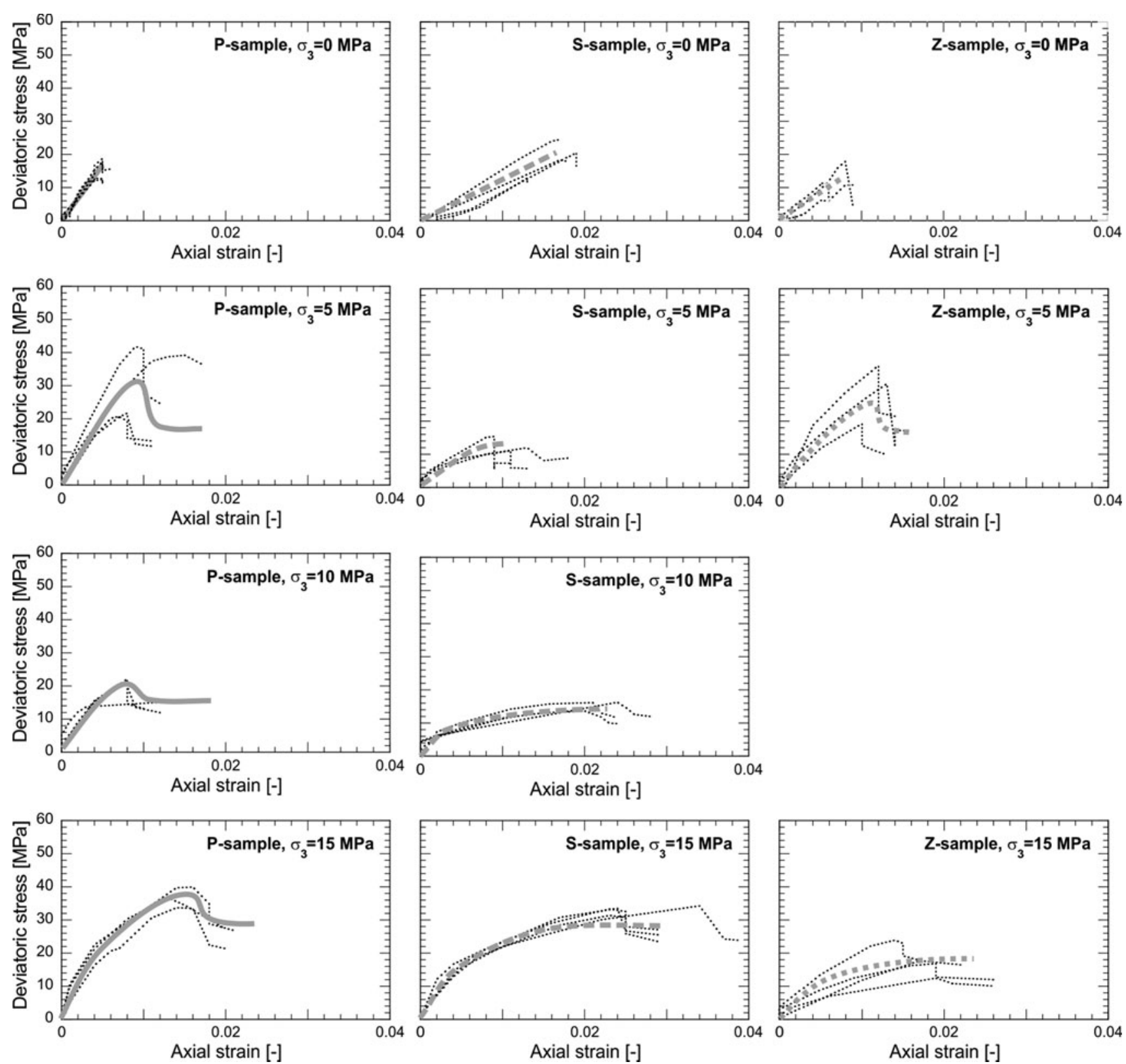

Fig. 5 Compilation of experimental results and average curves of triaxial tests for the three orientations of the axial loading and for the four confining pressures

plasticity for the volumetric behaviour, also called the "isotropic mechanism".

Being a cyclic model, Hujeux's model is capable of producing plastic deformation both upon loading and unloading. Actually the choice of Hujeux's model to represent the behaviour of the studied shale was not based on the cyclic aspects but principally on its ability to model induced anisotropy. The concept of multiple mechanisms of plasticity [18] allows the material behaviour to depend on the direction of loading, which is very convenient in the context of the modelling of mechanical anisotropy of rocks. The isotropic and deviatoric mechanisms produce plastic strain increments called $d \varepsilon_{i j}^{p \text {,iso }}$ and $d \varepsilon_{i j}^{p \text {,dev }}$, respectively. The total strain increment tensor, $d \varepsilon_{i j}$, is separated into elastic, $d \varepsilon_{i j}^{e}$, and plastic, $d \varepsilon_{i j}^{p}$, components as follows:

$d \varepsilon_{i j}=d \varepsilon_{i j}^{e}+d \varepsilon_{i j}^{p}$

The stress variables are defined as follows:

$p^{\prime}=\frac{1}{3}\left(\sigma_{x x}^{\prime}+\sigma_{y y}^{\prime}+\sigma_{z z}^{\prime}\right)$

$q=\left(\frac{3}{2} s_{i j} s_{i j}\right)^{1 / 2} \quad$ with $s_{i j}=\sigma_{i j}^{\prime}-p \delta_{i j}$ 

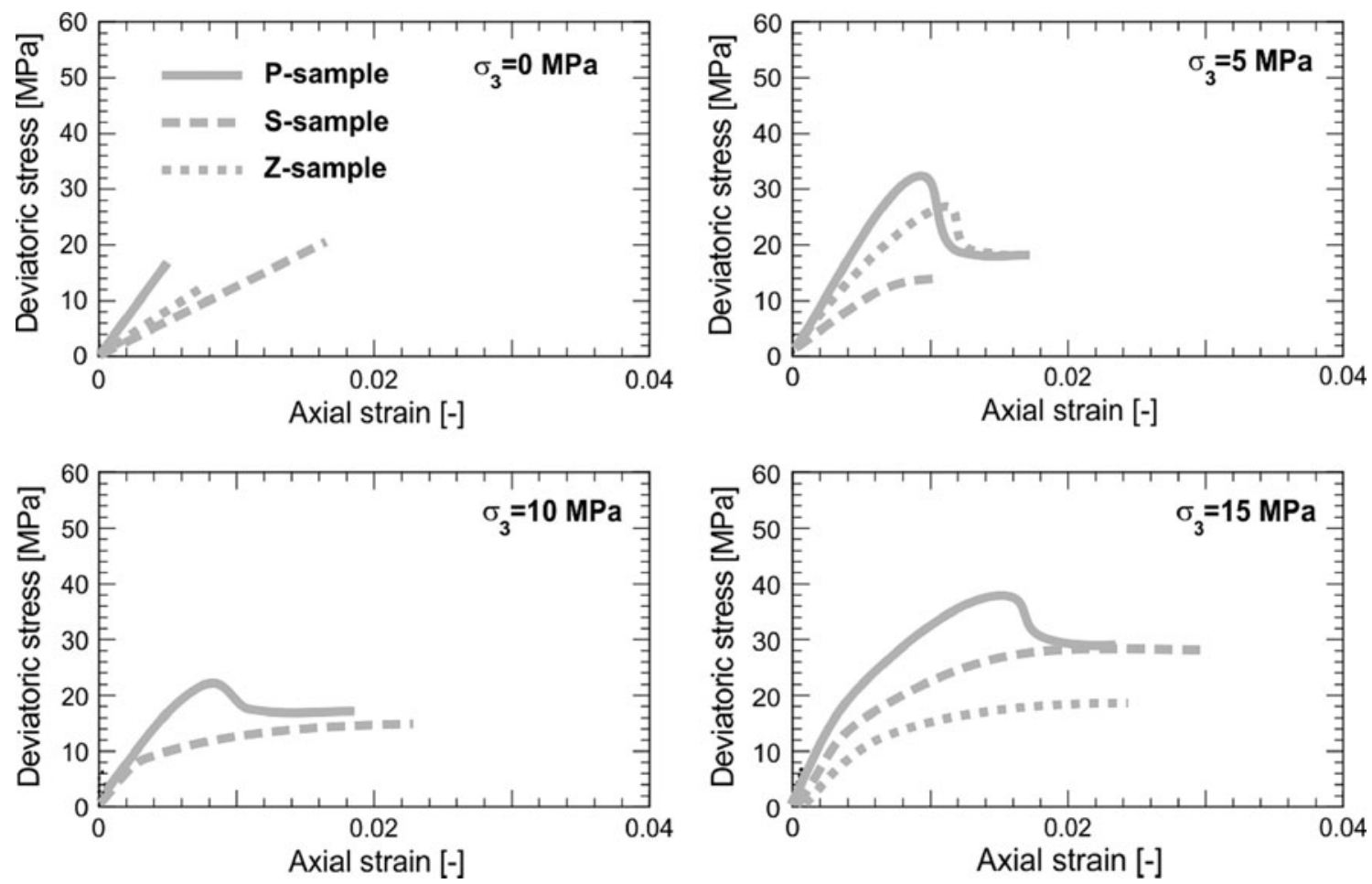

Fig. 6 Comparison of the typical responses of Opalinus Clay relative to the orientations of the axial loading for each confining pressure

$p_{k}^{\prime}=\frac{1}{2}\left(\sigma_{i i}^{\prime}+\sigma_{j j}^{\prime}\right)$

$q_{k}=\left(\frac{1}{4}\left(\sigma_{i i}^{\prime}-\sigma_{j j}^{\prime}\right)^{2}+\sigma_{i j}^{\prime 2}\right)^{1 / 2}$

where $(i, j, k)$ are circular permutations of $(x, y, z), p^{\prime}$ is the mean effective stress and $q$ is the deviatoric stress. In this study, the pore water pressure is assumed to be null, and thus, there is no difference between the effective and the total stresses.

\subsection{Elastic behaviour}

The elastic part of the model is nonlinear and isotropic. The elastic strain increment $d \varepsilon_{i j}^{e}$ is expressed as follows:

$d \varepsilon_{i j}^{e}=E_{i j k l}^{-1} d \sigma_{k l}^{\prime}$

In this case, $d \sigma_{k l}^{\prime}$ is the effective stress increment, and $E_{i j k l}^{-1}$ is the mechanical elastic tensor defined by the nonlinear bulk and shear moduli, $K$ and $G$, respectively,

$K=K_{\text {ref }}\left(\frac{p^{\prime}}{p_{\text {ref }}^{\prime}}\right)^{n^{e}} ; \quad G=G_{\text {ref }}\left(\frac{p^{\prime}}{p_{\text {ref }}^{\prime}}\right)^{n^{e}}$

where $p^{\prime}$ is the mean effective stress, $n^{e}$ the nonlinear elasticity exponent, $p_{\text {ref }}^{\prime}$ the reference pressure $K_{\text {ref }}$ and $G_{\text {ref }}$ the bulk and shear moduli at the reference pressure, respectively. Because the nonlinear elastic exponent is similar for the $K$ and $G$ moduli, the ratio between $K$ and $G$ remains constant, and therefore, the Poisson's ratio $v$ is not affected by the stress level. Equation [6] can be expressed in terms of Young's modulus E:

$E=E_{\mathrm{ref}}\left(\frac{p^{\prime}}{p_{\text {ref }}^{\prime}}\right)^{n^{e}} ; \quad v=c s t$

The elastic response of the material is isotropic, although the progressive anisotropic plastic strain hardening will induce a global anisotropic response even for small strains.

\subsection{Isotropic plastic mechanism}

The isotropic yield surface that bounds the elastic domain in the effective stress space is normal to the isotropic axis of stress (Fig. 7) and takes the following expression:

$f_{\text {iso }}=p^{\prime}-d p_{c r}^{\prime} r_{\text {iso }}$

where $d$ is a material parameter and $p_{c r}^{\prime}$ is the critical pressure in terms of effective stress. According to the bounding surface theory [4], $r_{\text {iso }}$ is the degree of plastification (mobilised hardening) of the isotropic yield limit. This enables a progressive evolution of the isotropic yield limit during loading. The evolution of $r_{\text {iso }}$ during loading is linked to the volumetric plastic strain induced by the 
isotropic mechanism, and the hardening law for the isotropic mechanism is calculated by:

$r_{\text {iso }}=r_{\text {iso }}^{\text {ela }}+\frac{\varepsilon_{v}^{p \text {,iso }}}{c+\varepsilon_{v}^{p, \text { iso }}}$

where $c$ is the volumetric hardening parameter and $r_{\text {iso }}^{\text {ela }}$ is the radius of the elastic domain of the isotropic mechanism. The parameter $c$ takes the value $c_{m}$ or $c_{\text {cyc }}$ depending on whether the loading scheme is monotonic or cyclic. In the formula, $\varepsilon_{v}^{p \text {,iso }}$ is the plastic component of the volumetric strain induced by the isotropic mechanism.

The flow rule of the isotropic mechanism is associated and assumes the following form:

$d \varepsilon_{i i}^{p \text {,iso }}=\frac{\lambda^{\text {iso }}}{3}$

The plastic multiplier $\lambda^{\text {iso }}$ is determined using the consistency equation for multi-dissipative plasticity [28].

\subsection{Deviatoric plastic mechanisms}

The decomposition of the deviatoric plastic response into three mechanisms is made in a fixed frame of reference $(\vec{x}, \vec{y}, \vec{z})$. For example, the yield limit associated with the deviatoric mechanism $k$ (Fig. 7) is defined by the function:

$f_{k}=q_{k}+\sin (\phi) p_{k}^{\prime} F_{k} r_{k}$

where $\phi$ is the friction angle mobilised at critical state. The function $F_{k}$ is obtained by:

$F_{k}=1-b \ln \left(\frac{p_{k}^{\prime}}{p_{c r}^{\prime}}\right)$

where $b$ is a material parameter that influences the shape of the yield surface. If $b=0$, the yield limit is the Mohr-Coulomb failure line, and if $b=1$, the yield surface is the Cam-Clay type. For the deviatoric mechanism $k$, the

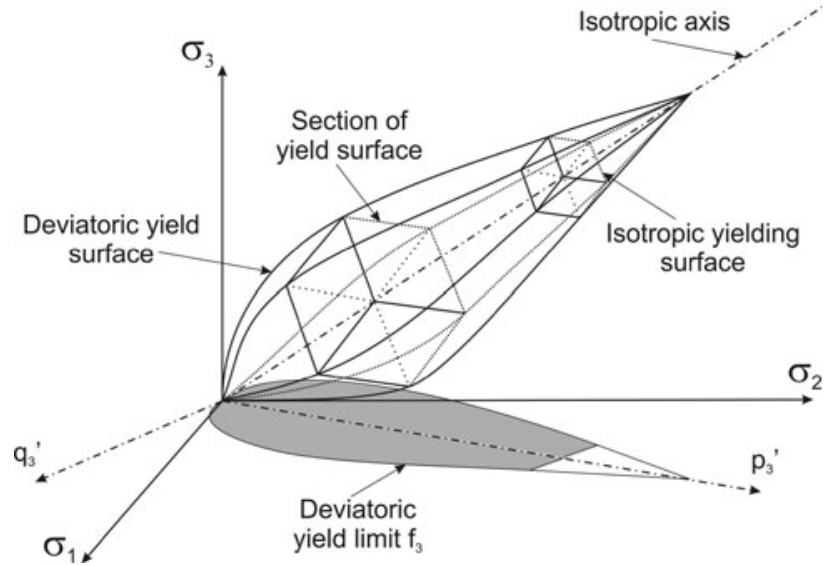

Fig. 7 Yield limits for the four-mechanism Hujeux's model in the principal stresses space degree of plastification $r_{k}$ depends on the plastic component of the deviatoric strain induced by the mechanism $k, \varepsilon_{q, k}^{p}$ :

$r_{k}=r_{k}^{e l a}+\frac{\varepsilon_{q, k}^{p}}{a+\varepsilon_{q, k}^{p}}$

with the parameter $a$ defined by:

$a=a_{\mathrm{cyc}}+\left(a_{m}-a_{\mathrm{cyc}}\right) \alpha_{k}$

where $a_{m}$ and $a_{\mathrm{cyc}}$ are material parameters of the hardening law of the deviatoric mechanisms ( $m$ : monotonous, cyc: cyclic), and $\alpha_{k}$ is a function of $r_{k}$ equal to 1 during primary loading.

The flow rules of the deviatoric mechanism $k$ assume the following forms:

$d \varepsilon_{q, k}^{p}=\lambda^{k} \psi_{k}^{d}$

$d \varepsilon_{v, k}^{p}=\lambda^{k}\left(\chi \alpha_{k}\left(\sin \theta+\frac{q_{k}}{p_{k}^{\prime}}\right)\right)$

where $\psi_{k}^{d}$ is a flow function and $\lambda^{k}$ the plastic multiplier, determined by Prager's consistency equation. In the formula, $\chi$ and $\theta$ are the dilatancy coefficient and dilatancy angle, respectively. $\theta=\phi$ and $\chi=1$ are the two conditions for the flow rule to be associated.

\subsection{Volumetric hardening}

A unique critical pressure $p_{c r}^{\prime}$ is defined for the four mechanisms that is the coupling variable between the plastic mechanisms. When the volumetric plastic strain is produced by one mechanism, the yield limits of the other mechanisms are modified. This parameter accounts for strain hardening in density:

$p_{c r}^{\prime}=p_{c r 0}^{\prime} \exp \left(\beta \varepsilon_{v}^{p}\right)$

where $\beta$ is the plastic compressibility, $\varepsilon_{v}^{p}$ is the sum of the plastic component of the volumetric strain induced by the four mechanisms and $p_{c r 0}^{\prime}$ is the initial critical pressure.

\section{Method for inducing anisotropy}

The anisotropic mechanical characteristics of Opalinus Clay may be attributed to two factors. First, there is a structural anisotropy attributable to the fabric because the long axis of the shale particles tends to align in a preferred horizontal direction during deposition. Second, there is an inherent anisotropy attributable to the stress history because the ground has undergone anisotropic loads such that vertical overburden stress differs from horizontal stress. It is commonly assumed that these structural and inherent anisotropies confer to the shale a transversely 
isotropic behaviour (or cross-anisotropic behaviour). The transverse plane corresponds with the bedding plane within which the material properties are the same in all directions. Below, the bedding plane will be associated with the directions $\vec{x}$ and $\vec{y}$, and the axis of symmetry (perpendicular to the bedding plane) is in the direction $\vec{z}$.

By definition, in Hujeux's model, it is possible to initialise the state of the material in a way that the stress history affects the shale properties differently in each direction of the space. The initialisation phase is comparable to preconsolidation (preloading) only in one or several directions. Therefore, an appropriate loading/unloading scheme can confer transversely isotropic behaviour on the material. The four steps of the simulation process are described below.

Step 1: Initial isotropic state. The parameters of the model are determined for an isotropic, virgin material. Figure $8 \mathrm{a}$ presents a scheme of an elementary volume of shale associated with the directions of the reference frame.

Step 2: Anisotropic preloading. This step enables initialising the material with the required initial, directiondependent properties. It has been established previously that the P-samples are the most rigid and have the highest peak shear strength. This indicates that stiffening has occurred within the bedding plane.

In Hujeux's model, the directional stiffening is induced by imposing a loading/unloading cycle in the chosen direction (Fig. 8b). For better control of the initialisation through plastic strain mechanisms, preloading is successively applied in each separate direction of the bedding plane $\vec{x}$ and $\vec{y}$ :

- The first load $\sigma_{x x}$ affects the yield limits $f_{y}$ and $f_{z}$, which are associated with the $y$ and $z$ deviatoric mechanisms (Eq. 12).

- The second load $\sigma_{y y}$ affects the yield limits $f_{x}$ and $f_{z}$, which are associated with the $x$ and $z$ deviatoric mechanisms.

Hardening may occur twice in the $z$ deviatoric mechanism and once in the $x$ and $y$ deviatoric mechanisms.

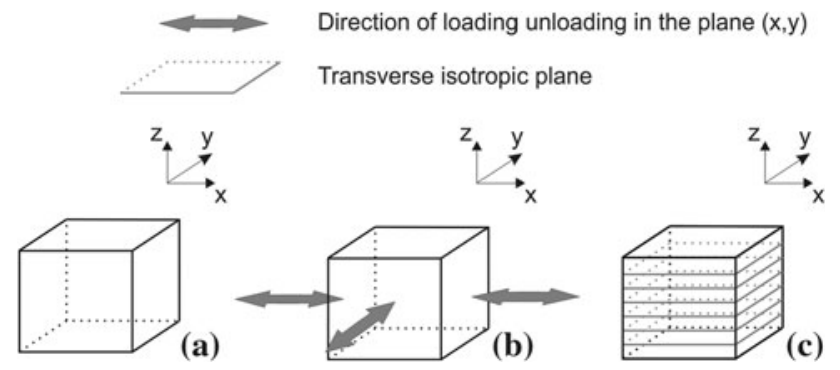

Fig. 8 Scheme of the initial elementary volume of the shale (a), Scheme of the anisotropic loading/unloading applied to the shale (b), Scheme of the elementary volume of the shale after the preloading (c)
The value of the preloading in the $\vec{x}$ and $\vec{y}$ directions may be adjusted with the help of the test results of the P-samples based on the size of the elastic domain and the peak shear strength. It is noted that during the initialisation phase, each preload is followed by unloading.

Step 3: Anisotropic state. At this stage, the mechanical history of the material varies in the three directions of space. The preloading modified the parameters of the model, especially the degrees of plastification, $r_{k}$ (Eq. 14).

This will induce an anisotropic response of the material. Because the preloading was equal in the $\vec{x}$ and $\vec{y}$ directions, cross-anisotropy was induced and the transverse plane corresponds to the bedding plane (Fig. 8c).

At this step, the $\mathrm{S}$-sample, $\mathrm{P}$-sample and $Z$-sample presented previously in Fig. 1 may be identified by rotating the reference frame. Figure 9 shows the orientation of the reference frame to consider if the loading direction is vertical.

Step 4: Triaxial shearing path. At this stage, the numerical sample has a cross-anisotropic behaviour induced by the preloading. Step 4 is dedicated to the simulation of triaxial shearings in three directions: perpendicular, parallel and with an angle of $45^{\circ}$ the bedding plane to reproduce the experimental results obtained with the $\mathrm{S}$-samples, $\mathrm{P}$-samples and $Z$-samples. Figure 10 is a redrawing of Fig. 9 with a rotation of the load instead of a rotation of the reference frame. The shearing is that of a conventional triaxial compression test, that is to say that starting from a given isotropic state of stress (confining pressure), axial deformation is imposed in only one direction. For the sake of clarity in the discussions regarding Hujeux's model, the imposed directional deformation will be considered as an imposed directional stress called "the shearing load". The confining pressure is maintained constant in the plane perpendicular to the shearing direction.

The response of Hujeux's model to the various types of loading is as follows:

- The shearing of the P-samples is such that the direction of loading is within the bedding plane. The axis $\vec{x}$ is
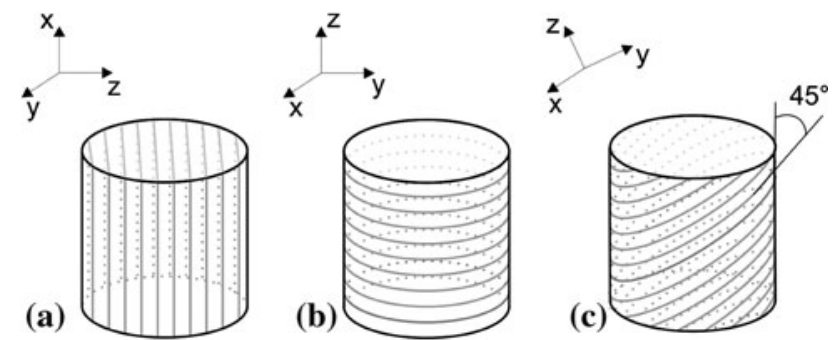

Fig. 9 Schemes of the P-sample (a), S-sample (b) and Z-sample (c), with the orientation of the reference frame 
arbitrarily chosen as the loading direction in the P-samples, but shearing along the $\vec{y}$ direction would give the same results. The shearing load $\sigma_{x x}$ will induce deviatoric stresses $q_{y}$ and $q_{z}$, and therefore, the behaviour of the P-samples depends on the mobilisation of the $y$ mechanism (yield limit $f_{y}$ ) and the $z$ mechanism (yield limit $f_{z}$ ). It is recalled that the $z$ mechanism underwent more hardening than the other two mechanisms at step 2, showing that the P-samples will appear to be more overconsolidated.

- In the opposite configuration of the S-samples, the loading direction is normal to the bedding plane, and therefore, a shearing load $\sigma_{z z}$ is imposed. In response to the generated deviatoric stresses $q_{x}$ and $q_{y}$, the mobilised plastic strain mechanisms are the $x$ mechanism (yield limit $f_{x}$ ) and the $y$ mechanism (yield limit $f_{y}$ ). Those two mechanisms have been activated only once, at step 2. The S-samples will thus appear less overconsolidated than the P-samples.

- The response to Hujeux's model for the Z-samples is less easily interpreted because of the inclination of the shearing load (combination of $\sigma_{x x}$ and $\sigma_{z z}$ ). All of the deviatoric plastic mechanisms are mobilised during shearing. In essence, the relative mobilisation of each mechanism yields that the modelled response of $Z$-samples is intermediary between the other two responses.

\section{Numerical simulations}

\subsection{Material parameters}

Provided that the history of stress has a significant influence on the predicted response, the tests to be used for the calibration of material parameters should be chosen carefully. The parameters attributed to the tested materials are intrinsic material parameters, meaning that they are related to the virgin state of the material before any stress-induced anisotropy occurs. Consequently, tests for which the

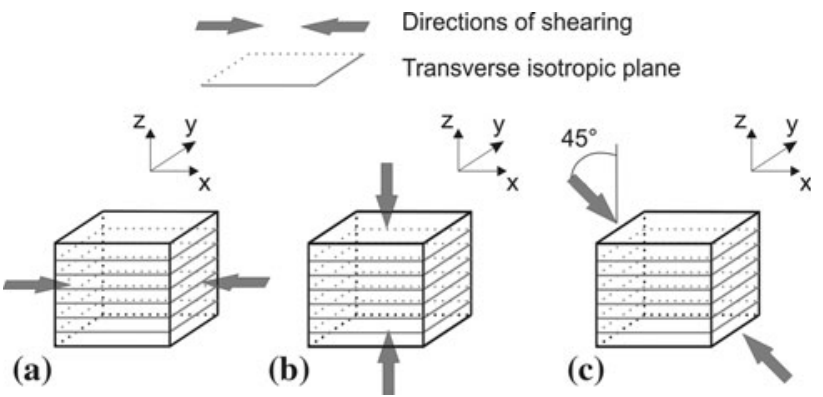

Fig. 10 Triaxial shearing directions for the P-sample (a), S-sample (b) and Z-sample (c) preconsolidation is minimal are preferred for the calibration of Hujeux's model. Regarding the results on Opalinus Clay presented in part 1 , the S-samples (in which the loading direction is perpendicular to the loading plane) are apparently the less overconsolidated samples. As explained in the previous section, the preloading that induces the anisotropic features is performed in the plane $(\vec{x}, \vec{y})$, and therefore, the behaviour of the material corresponding to the direction $\vec{z}$ can be considered close to virgin for the $\mathrm{S}$-samples. The latter will thus be used for the determination of the parameters of the model at step 1 (material assumed as isotropic).

The material parameters were determined based on the interpretation of the experimental results presented in the first section. Details on the method used for parameter determination can be found in [15].

Because of the lack of accuracy in the volumetric plane, the Poisson's ratio is difficult to assess. It has been assumed to be equal to 0.15 . The Young's modulus was assumed to be affected by the stress level: $E=1,162\left(\sigma_{3}\right)^{0.9} \mathrm{MPa}$, in agreement with the nonlinear elasticity of Hujeux's model.

The isotropic and deviatoric plastic parameters were calibrated using the triaxial tests carried out on the $\mathrm{S}$-sample at $5 \mathrm{MPa}$ of confining pressure (Fig. 3b). In summary, the calibration process is based on the following steps:

- Setting up the critical state parameters to account for the failure

- Setting up the size and shape of the yield surfaces (Eq. 9 and 12) to account for the initiation of plasticity and the hardening process. Usually, a very progressive plasticity is targeted with Hujeux's model.

The list of parameters is reported in Table 1. It is recalled that due to the cyclic formulation of Hujeux's model, some plasticity may be observed upon unloading. However, with the set of parameters that has been used, for any given plastic mechanism, the degree of plastification (cyclic activation) is on average 4 times lower than the monotonic degree of plastification, which means that the cyclic terms have a minor contribution to the modelled elasto-plastic behaviour.

\subsection{Simulation of triaxial shearing tests}

It can be concluded from the previous paragraph that the interest of Hujeux's model lies in the definition of a set of material parameters related to the behaviour of the original isotropic, virgin material, the anisotropy being induced by the means of the stress history. The loading scenario was established on the basis of realistic values of stress regarding the depth of the sample and the geological profile of the site. 
The preloading within the assumed bedding plane $(\vec{x}, \vec{y})$ reached $7 \mathrm{MPa}$.

Hujeux's model is a critical state model with no cohesion. Similar to the modified Cam-Clay model, the state of stress needs to be initialised to a non-null value to avoid hitting the critical state line at low pressures [31]. At very low confining stresses (as for unconfined compression tests), the lack of cohesion at residual state is a limitation of the model. However, this model may accommodate cohesion at the peak strength, followed by a softening response. To model unconfined compressions, an initial isotropic stress of $1 \mathrm{MPa}$ was used.

Before assessing the quantitative capabilities of the model in predicting the stress-strain response during shearing for the $\mathrm{P}-, \mathrm{S}$ - and Z-samples, it is proposed to analyse the qualitative evolution of the predicted stiffness and residual states, depending on the sample type. The most representative planes are those expressing deviatoric stress versus axial strain. Figure 11 presents an overview of the effect of induced anisotropy over the predicted sample response during conventional shearing. Even if the elastic part of the model is considered as isotropic, the progressive mobilisation of the plastic mechanism at small strains allows the reproduction of cross-anisotropy in the pseudoelastic range.

The preloadings within the bedding plane have three direct effects:

- The samples exhibit a stiffer behaviour if the axial (shearing) load is parallel to the bedding plane
(P-sample) than for any other angle of load (S- and Z-samples)

- The stress-strain curves obtained for the Z-samples are between those of the $\mathrm{P}$ - and $\mathrm{S}$-samples for the main part of strain range.

- For the lowest confining pressure (0 MPa), the induced anisotropy is such that the response of the P-sample and that of the S-sample are fundamentally different: whereas the P-sample exhibits a peak followed by slight softening, the S-sample will harden progressively in a ductile fashion.

These mechanisms are caused by the various degrees of plastification $r_{k}$ of the deviatoric mechanisms having different values at the start of shearing from one direction (e.g. $\vec{x}$ ) to another (e.g. $\vec{z}$ ). For example, at the end of the preloading phase, $r_{x}=0.738$ and $r_{z}=0.794$. This difference is also amplified by having chosen adequate values for parameters $a_{m}, a_{\mathrm{cyc}}, r_{\mathrm{dev}}^{\mathrm{ela}}$. During shearing, depending on the direction of the load, the hardening process is as a consequence more or less progressive.

These conclusions confirm that the anisotropy induced by preloading (i.e. preactivation of various deviatoric plastic mechanisms) significantly influences the stiffness, the size of the elastic domains and the propensity towards hardening or softening. So, in this approach and for this particular material (for which diagenesis is probably not the main source of anisotropy), the specifications of the rheological behaviour can be met without introducing explicit material anisotropy in the constitutive model.

Table 1 Material parameters of Opalinus Clay according to the four-mechanism Hujeux model

Values

Elastic parameters

$E_{\text {ref }} \quad[\mathrm{MPa}]$

Young's modulus at a reference mean effective pressure $p_{\text {ref }}^{\prime}(=1 \mathrm{MPa})$

1,162

$v \quad[-]$

Poisson's ratio

0.15

$n^{e} \quad[-] \quad$ The exponent of nonlinear elasticity

0.9

Isotropic plastic parameters

$p_{c r 0}^{\prime} \quad[\mathrm{MPa}] \quad$ Initial critical pressure $\quad 10$

$\beta \quad[-] \quad$ Plastic compressibility modulus 35

$r_{\text {iso }}^{\text {ela }} \quad[-] \quad$ Ratio of the size of the isotropic elastic nucleus relative to the size of the external deviatoric yield limit 0.01

c [-] Control of the progressive plasticity within the external isotropic yield limit 0.002

$c_{\mathrm{cyc}} \quad[-] \quad$ Control of the progressive plasticity within the external isotropic yield limit for cyclic loading 0.001

$d \quad[-] \quad$ Ratio between the Cam-Clay critical pressure and the preconsolidation pressure 2

Deviatoric plastic parameters

$b \quad[-] \quad$ Control the shape of the deviatoric yield limit 1

$\phi \quad\left[{ }^{\circ}\right] \quad$ Friction angle at critical state 33

$\chi \quad[-] \quad$ Flow rule parameter 1

$\theta \quad\left[{ }^{\circ}\right] \quad$ Dilatancy angle 28

$r_{\mathrm{dev}}^{\mathrm{ela}} \quad[-] \quad$ Ratio of the size of deviatoric elastic nucleus relative to the size of the external deviatoric yield limit 0.001

$a_{m} \quad[-] \quad$ Control of the progressive plasticity within the external deviatoric yield limit $\quad 0.002$

$a_{\mathrm{cyc}} \quad[-] \quad$ Control of the progressive plasticity within the external deviatoric yield limit for cyclic loading 0.001 

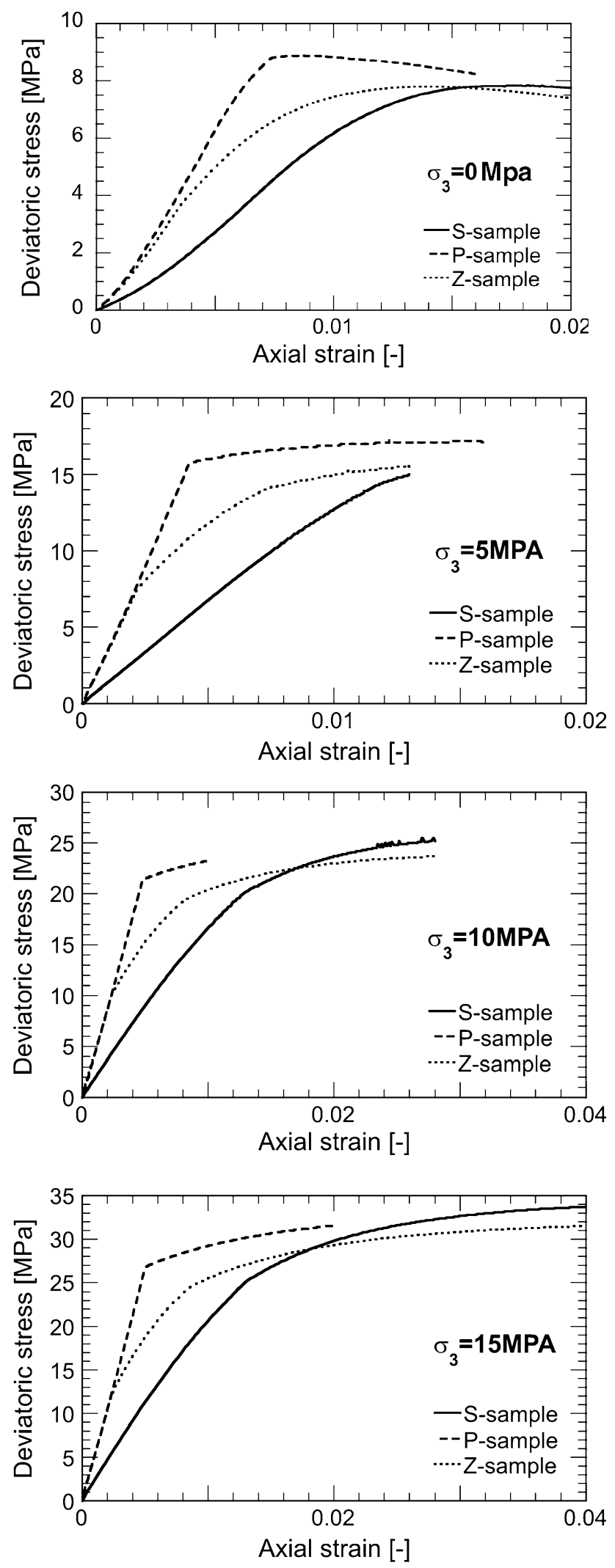

Fig. 11 Comparison of numerical results obtained on the P-sample, $\mathrm{S}$-sample and $\mathrm{Z}$-sample. The confining pressures are a $0 \mathrm{MPa}$, b $5 \mathrm{MPa}$, c $10 \mathrm{MPa}$ and d $15 \mathrm{MPa}$
In the simulation of the shear tests, axial deformation is imposed while keeping a constant confining pressure. The maximum axial strain in each simulation is that of its respective experimental result. Therefore, in Fig. 11, the simulations stop at a target maximum axial strain that is different in the P-samples, S-samples and Z-samples. The fact that a simulation has ended does not always signify that the material has reached a residual state of failure.

Figures 12, 13 and 14 compare the numerical simulations with the experimental results of uniaxial and triaxial compression tests in the three directions of loading (P-, S- and Z-samples). Those results are expressed in the deviatoric plane ( $q$ versus $\varepsilon_{1}$ ) and volumetric plane $\left(\varepsilon_{v}\right.$ versus $\left.\varepsilon_{1}\right)$.

In Fig. 12, the P-sample shows the stiffer behaviour because the activation of the plastic mechanisms occurs at high strains. Consequently, the full elastic stiffness develops in the first part of the curve. This elastic rigidity is well reproduced as a function of the confining pressure through nonlinear elasticity, excepted for the unconfined compression for which the rigidity predicted by the model underestimates the real rigidity. The brittle behaviour experimentally observed in the P-sample is not reproduced by the constitutive model because it is likely attributable to strain localisation and loss of homogeneity in the sample. At our constitutive level, this feature of behaviour is not included.

In Fig. 13, the numerical simulation of shearing for the $\mathrm{S}$-samples at various confining pressures shows that hardening is more progressive, with an acceptable quantitative prediction. The S-sample is clearly softer (in its "pseudoelastic" response) and more ductile (in the plastic part) than the P-sample. This soft "pseudo-elastic" response is taken into account by the model through the progressive activation of a plastic mechanism from the beginning of the compression, inducing progressiveness and ductility of the behaviour. The initial slope of the curves at different confining pressures is relatively well reproduced by the model. The peak strength fit well for 5 and $15 \mathrm{MPa}$ of confining pressures while the model underestimates the unconfined strength and overestimates the strength at $10 \mathrm{MPa}$ of confinement. This is probably due to the fact that the residual state criterion is not a straight line as predicted by the Cam-Clay type model.

Figure 14 shows that the initial rigidity of Z-samples is included between P-sample and S-sample. The strength is relatively well reproduced, excepted for the $15 \mathrm{MPa}$ for which the numerical simulations overestimates the resistance. No experimental data are available for the confinement of $10 \mathrm{MPa}$. However, the numerical results has been represented in order to compare the obtained results under different confining pressure.

Although the experimental measurements of the volumetric strains might not always be accurate, the 
(a)

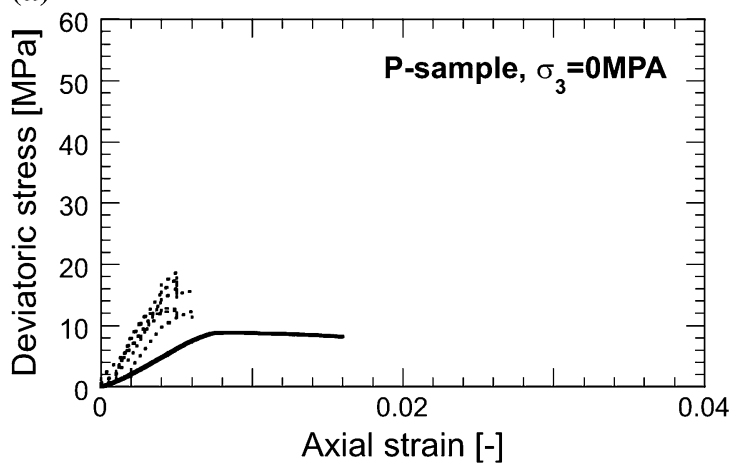

(c)
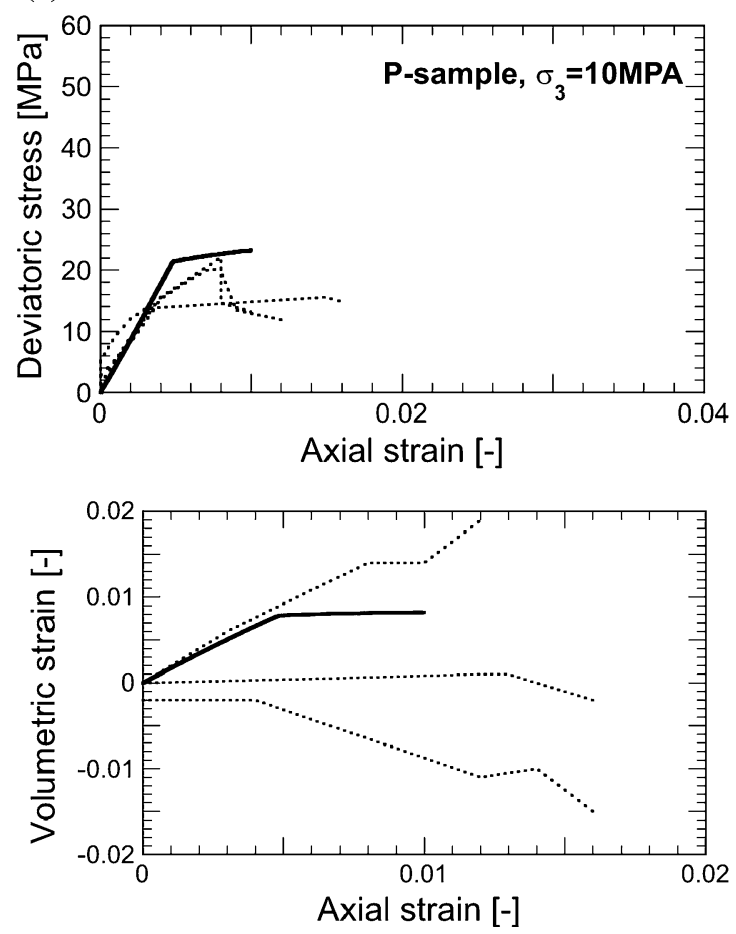

(b)
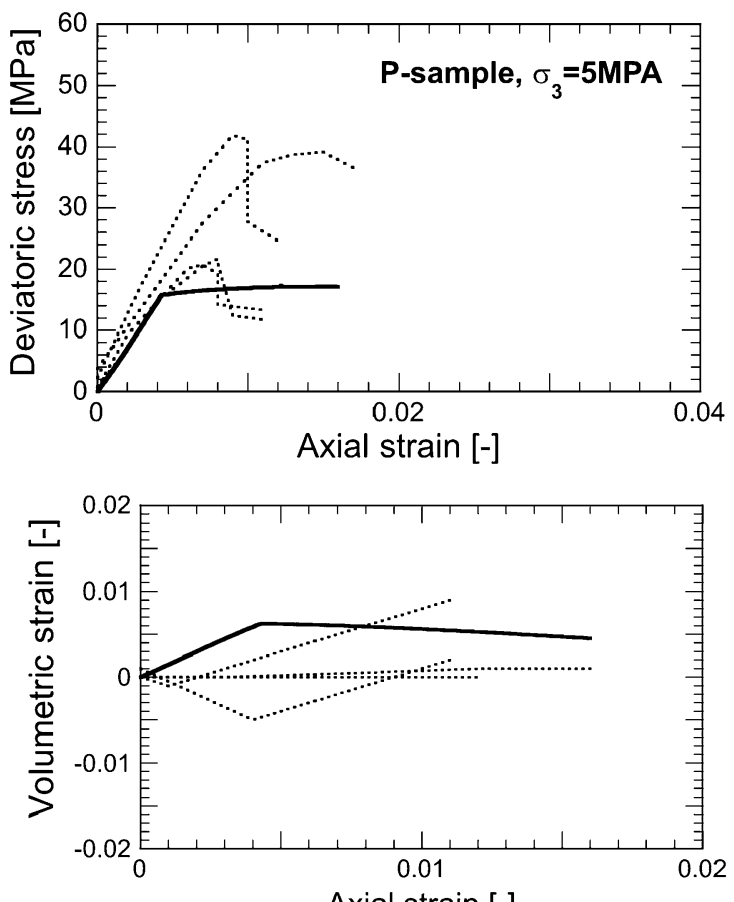

(d)
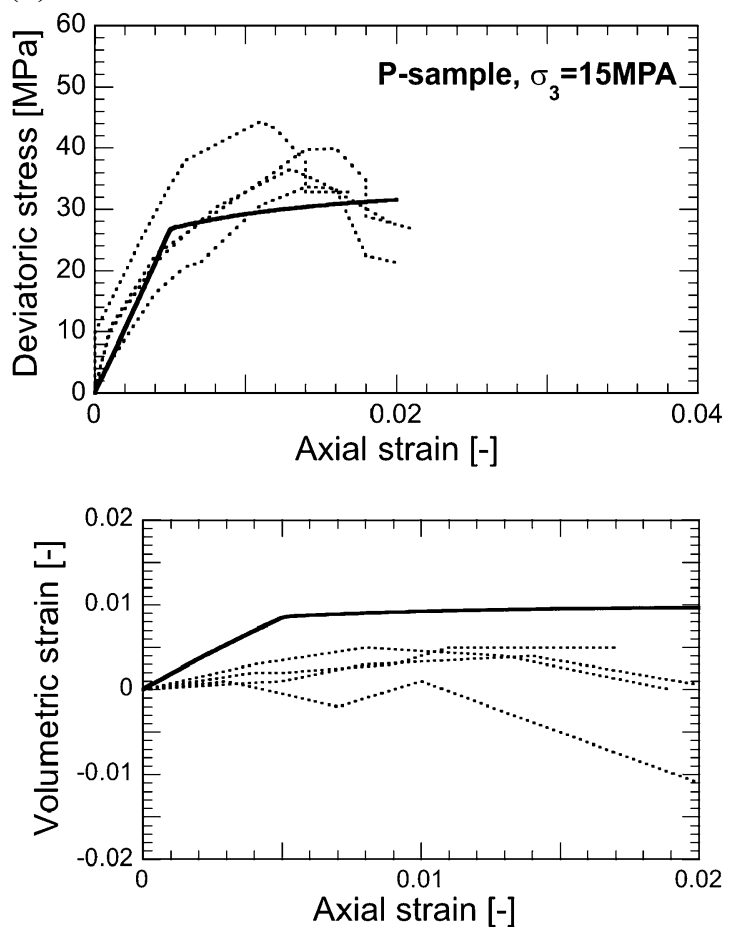

Fig. 12 Compilation of triaxial tests on Opalinus Clay with axial loading parallel to the bedding plane (P-sample). The confining pressures are a $0 \mathrm{MPa}$, b $5 \mathrm{MPa}$, c $10 \mathrm{MPa}$ and d $15 \mathrm{MPa}$. Dotted lines: experimental results; solid lines: numerical results

orders of magnitude of the simulated volumetric deformations are satisfactory. It is recalled that the volumetric response of the sample is in correlation with the conditions of drainage and saturation. Because those two aspects are not well controlled during experimental tests, it is irrelevant to compare quantitatively the numerical simulations with the experimental volumetric response. 

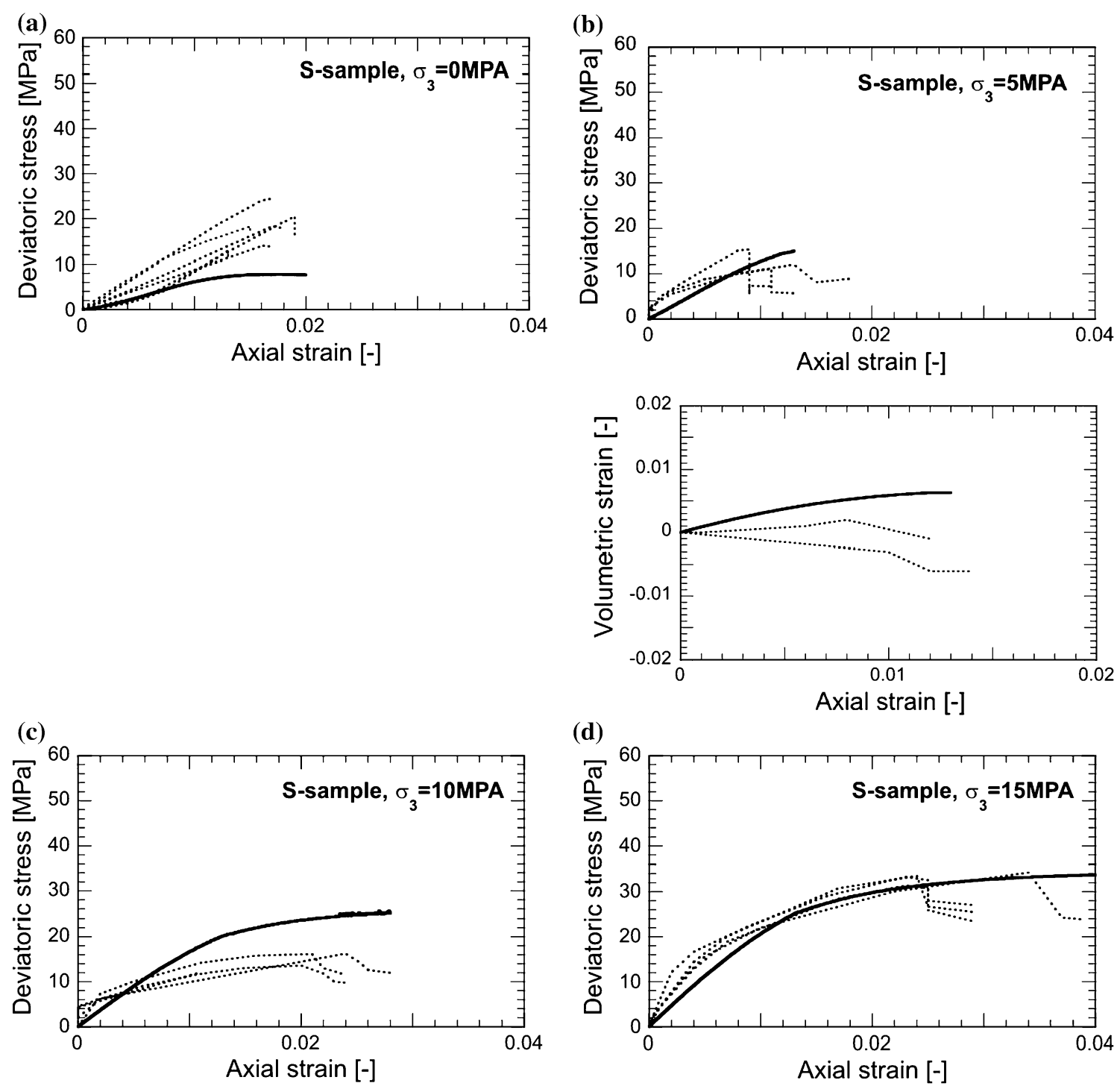

(d)
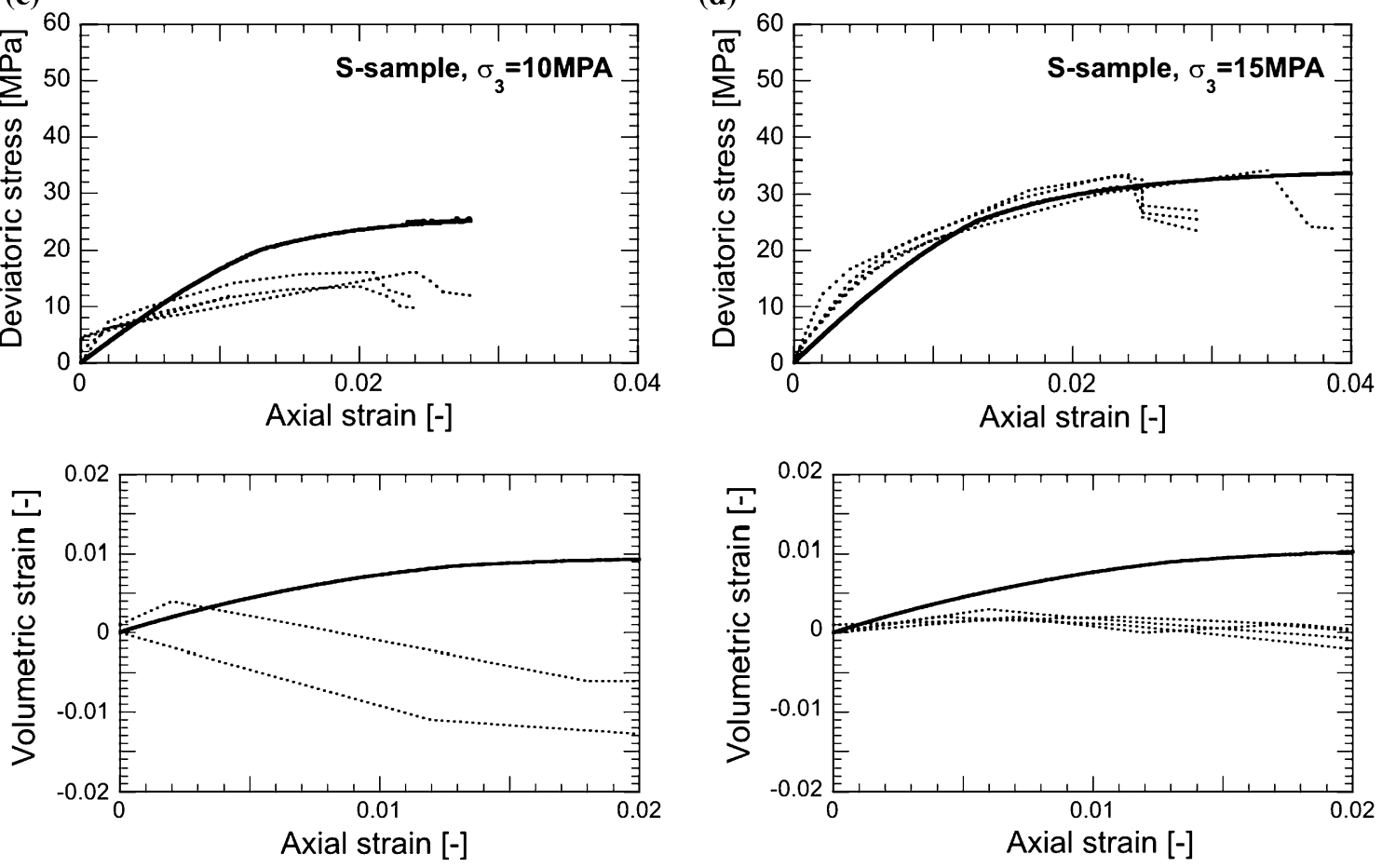

Fig. 13 Compilation of triaxial tests on Opalinus Clay with axial loading perpendicular to the bedding plane (S-sample). The confining pressures are a $0 \mathrm{MPa}$, b $5 \mathrm{MPa}$, c $10 \mathrm{MPa}$ and d $15 \mathrm{MPa}$. Dotted lines: experimental results; solid lines: numerical results

\section{Conclusions}

The purpose of this study was to characterise the main features of the anisotropic behaviour of Opalinus Clay and to identify an anisotropic constitutive framework validated through numerical simulations of triaxial tests done on Opalinus Clay samples.

The first part of the study was dedicated to analysing the large quantity of available laboratory tests that characterise the mechanical responses of Opalinus Clay. Those tests 
(a)

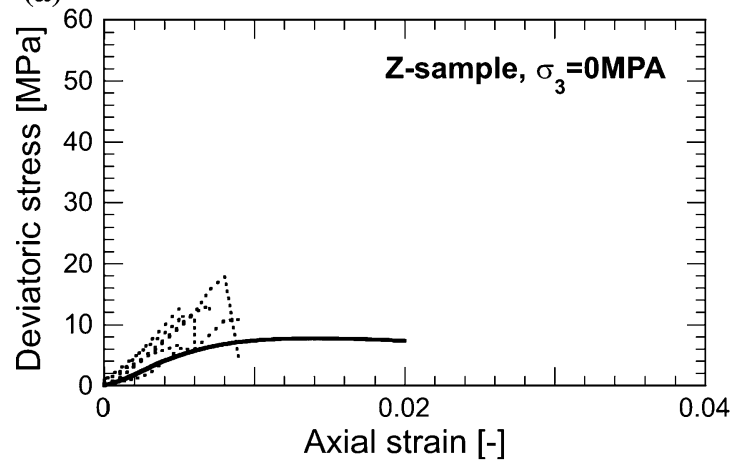

(c)
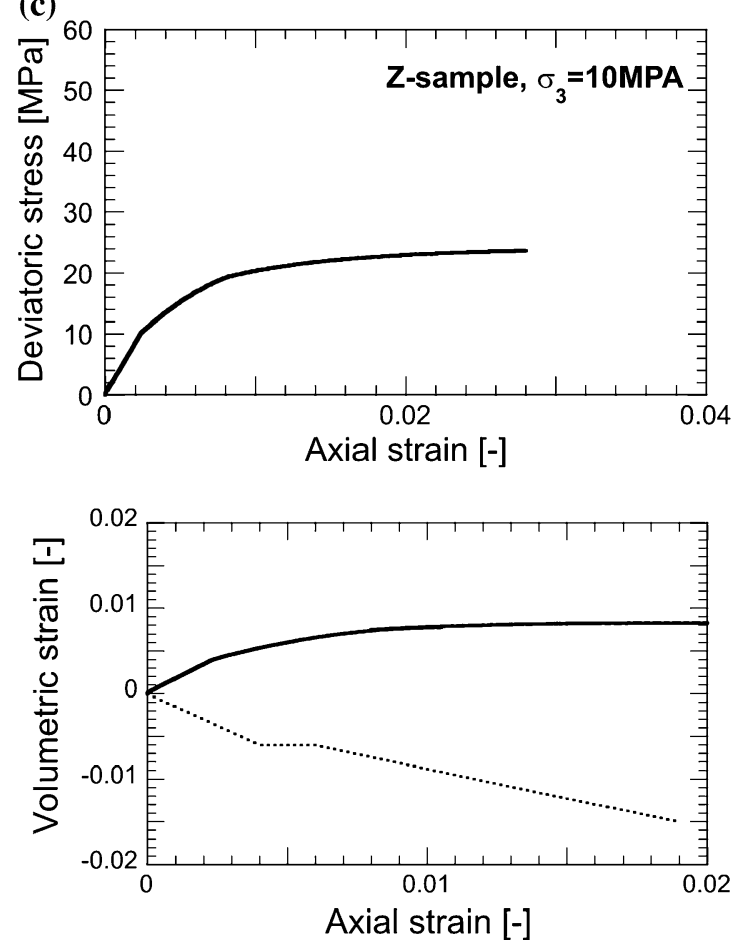

(b)
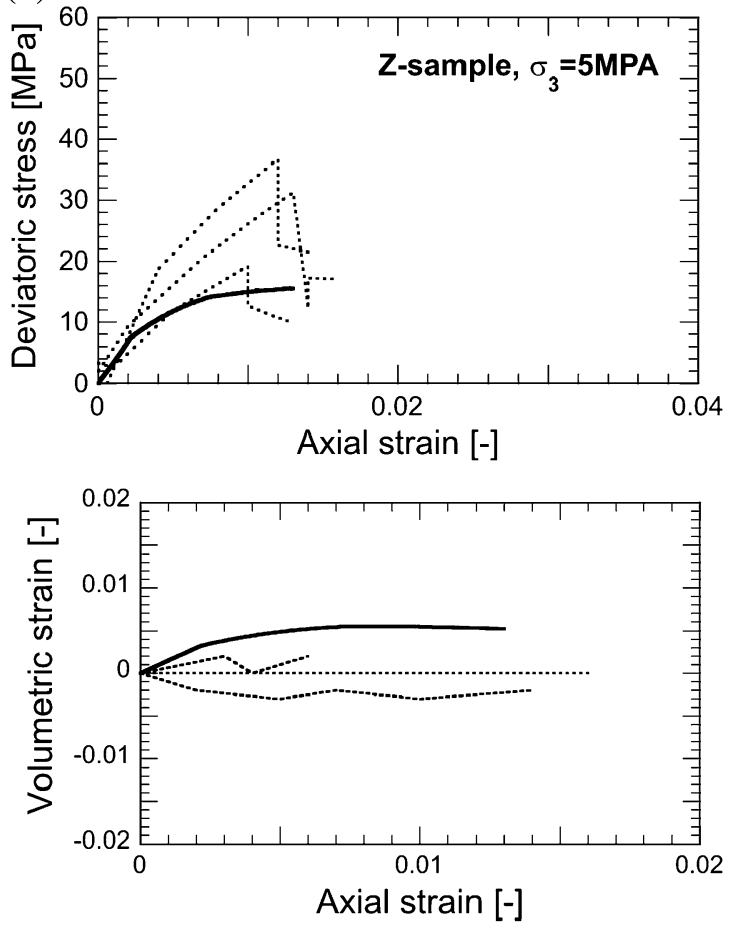

(d)
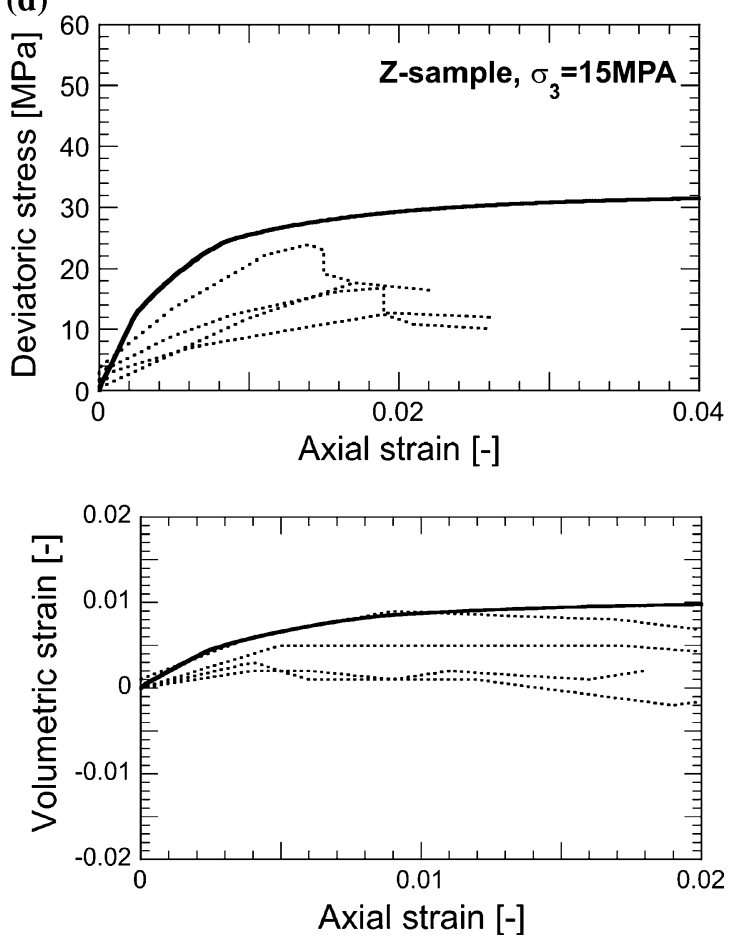

Fig. 14 Compilation of triaxial tests on Opalinus Clay with axial loading oriented at $45^{\circ}$ relative to the bedding plane (Z-sample). The confining pressures are a $0 \mathrm{MPa}$, b $5 \mathrm{MPa}$, c $10 \mathrm{MPa}$ and d $15 \mathrm{MPa}$. Dotted lines: experimental results; solid lines: numerical results

consist mainly of uniaxial compression tests and triaxial tests. From these results, the typical response of the material in each direction of its anisotropy has been deduced. In this material, clear bedding can be identified. The behaviour is cross-anisotropic (i.e. it is isotropic in the plane of the bedding, and the only direction of anisotropy is perpendicular to the bedding). The oriented fabric of the material has been considered here through a mechanical preloading that activates hardening processes in order to strengthen the material in some specific directions. 
Consequently, it appeared that the stress history induces a typical response of the material, which is more overconsolidated when it is loaded parallel to the bedding plane (P-sample) than when loaded perpendicular to the bedding plane (S-sample).

The capabilities of Hujeux's model have been assessed in reproducing the anisotropic features of the behaviour of Opalinus Clay through numerical investigations. Our purpose was to show that it is possible to reproduce mechanical anisotropy with a model that is a priori isotropic. The constitutive model uses the theory of multimechanism plasticity. The preliminary activation of deviatoric plastic mechanisms by preloading the samples in chosen directions allows the generation of anisotropy. The model formulation features four mechanisms of strain plasticity that are alternately mobilised depending on the direction of loading. The three deviatoric plastic mechanisms are assigned to the three principal directions of anisotropy. In the present case, prestressing was applied in the bedding plane. The predicted stress-strain response is different for the S-, P- and Z-samples because the hardening process is different, depending on the number of plastic mechanisms that are mobilised.

Three fundamental observations account for the adequacy of the chosen constitutive framework and preloading strategy: (1) the elastic moduli depend on the direction of shearing, (2) the response of the Z-samples $\left(45^{\circ}\right)$ is between those of the P-samples $\left(90^{\circ}\right)$ and the S-sample $\left(0^{\circ}\right)$ and (3) induced anisotropy will influence the way the material hardens or softens, depending on the angle of shearing.

The predictions using Hujeux's model showed overall good agreement with the experimental data expressed in terms of deviatoric stress versus axial strain. The quantitative predictions of the volumetric strains during shearing show a lower comparability, which could be attributed to the difficulty of controlling drainage conditions during the experimental tests.

It is important to point out that in this approach, the nonmechanical source of anisotropy (such as diagenesis or cementation) has not been considered. It is clear that for some rocks, when diagenesis or cementation plays a major role on the anisotropy of the materials, the model could be improved by adding an explicit directional dependency of the mechanical behaviour.

It is often improperly believed that the response of such stiff sedimentary material is mainly governed by a large elastic domain ended by a failure criterion. There are cases where the elastic-perfectly plastic approach is an abusive simplification of a more complex elasto-plastic response with strain hardening. This study shows that a model based on the critical state theory, which is commonly used for fine-grained soils, is well adapted to reproduce the main features of behaviour of the Opalinus Clay. This is relevant primarily under high confining pressures, as is the case at the studied depth.

Acknowledgements The authors thank the Swiss National Cooperative for the Disposal of Radioactive Waste (NAGRA) for providing the experimental results. The authors also thank Prof. D. Aubry (Ecole Centrale Paris) and Prof. H. Modaressi (BRGM) for providing the driver for the Hujeux's model.

\section{References}

1. Boehler JP, Sawczuk A (1977) On yielding of oriented solids. Acta Mech 27:185-206

2. Bossart P, Meier P, Moeria A, Trick T, Mayor JC (2002) Geological and hydraulic characterisation of the excavation disturbed zone in the Opalinus Clay of the Mont Terri Rock Laboratory. Eng Geol 66(1-2):19-38

3. Chiffeleau S, Robinet JC (1980) HE experiment: determination of the hydromechanical characteristics of the Opalanius Clay. Mont Terri Project, Technical Report p 98-136

4. Dafalias Y, Herrmann L (1980) A bounding surface soil plasticity model. International symposium on soils under cyclic and transient loading, Swansea p 335-345

5. Duveau G, Shao JF, Henry JP (1998) Assessment of some failure criteria for strongly anisotropic geomaterials. Mech Cohes-Frict Mater 3:1-26

6. Donath FA (1961) Experimental study of shear failure in anisotropic rocks. Geol Soc Am Bull 72:985

7. François B, Collin F, Dizier A, Charlier R (2011) Development of an extended Drucker-Prager hardening model for cross-anisotropy of soft rocks. 2nd international symposium on computational geomechanics (ComGeo II), Cavtat-Dubrovnik, Croatia, p 142-152

8. Gens A, Vaunat J, Garitte B, Wileveau Y (2007) In situ behaviour of a stiff layered clay subject to thermal loading: observations and interpretation. Géotechnique 57(2):207-228

9. Giraud A, Gruescu C, Do DP, Homand F, Kondo D (2007) Effective thermal conductivity of transversely isotropic media with arbitrary oriented ellipsoïdal inhomogeneities. Int J Solids Struct 44(9):2627-2647

10. Gowd TN, Rummel F (2003) Effect of confining pressure on the fracture behaviour of a porous rock. Int J Rock Mech Min Sci Geomech 17:225-229

11. Hoek E (1983) Strength of jointed rock masses. Geotechnique 33(3):187-223

12. Hujeux J (1985) Une loi de comportement pour le chargement cyclique des sols, Génie Parasismique, (V. DAVIDOVICI. Ed.), Presses de l'E.N.P.C, p 287-302

13. Hsu S-C, Nelson PP (2002) Characterization of Eagle Ford shale. Eng Geol 67(1-2):169-183

14. Ibanez WD, Kronenberg AK (1993) Experimental deformation of shale: mechanical properties and microstructural indicators of mechanisms. Int J Rock Mech Min Sci Geomech Abstr 30(7): 723-734

15. Laloui L, François B (2008) Benchmark on constitutive modeling of the mechanical behaviour of Opalinus Clay. Mont Terri Project, Technical Report

16. Lash GG, Blood DR (2004) Origin of shale fabric by mechanical compaction of flocculated clay: evidence from upper Devonian Rhinestreet Shale, Western New York, USA. J Sediment Res 74:110-116

17. Lekhnitskii SG (1977) Theory of elasticity of an anisotropic elastic body, 2nd edn. MIR Publishers, Moscow 
18. Mandel W (1965) Généralisation de la théorie de Koiter. Int J Solids Struct 1:273-295

19. Marschall P, Horseman S, Gimmi T (2005) Characterisation of gas transport properties of the Opalinus Clay, a potential host rock formation for radioactive waste disposal oil and gas science and technology. Revue de l'Institut Français du Pétrole 60(1): 121-139

20. McLamore R, Gray KE (1967) The mechanical behavior of anisotropic sedimentary rocks. J Eng Ind Trans ASME 89:62-73

21. Nagra (2002) Projekt Opalinuston-synthese der geowissenschaftlichen Untersuchungs-ergebnisse. Entsorgungsnachweis für abgebrannte Brennelemente, verglaste hochaktive sowie langlebige mittelaktive Abfälle. Nagra Technical Report NTB 02-03, Nagra, Wettingen, Switzerland

22. Niandou H, Shao JF, Henry JP, Fourmaintraux D (1997) Laboratory investigation of the mechanical behaviour of Tournemire shale. Int J Rock Mech Min Sci 34(1):3-16

23. Nova R (1980) The failure of transversely isotropic rocks in triaxial compression. Int J Rock Mech Min Sci Geomech Abstr 17(6):325-332

24. Oda M, Nemat-Nasser S, Konishi J (1985) Stress-induced anisotropy in granular masses. Soils Found 25(3):86-97

25. Pietruszczak S, Lydzba D, Shao JF (2002) Modelling of inherent anisotropy in sedimentary rocks. Int J Solids Struct 39:637-648

26. Pietruszczak S, Mroz Z (2001) On failure criteria for anisotropic cohesive-frictional materials. Int J Numer Anal Meth Geomech 25:509-524

27. Popp T, Salzer K (2007) Anisotropy of seismic and mechanical properties of Opalinus Clay during triaxial deformation in a multi-anvil apparatus. Phys Chem Earth 32(8-14):879-888

28. Rizzi E, Maier G, Willam K (1996) On failure indicators in multidissipative materials. Int J Solids Struct 33(20-22):3187-3214
29. Salager S, Nuth M, Marschall P, Laloui L (2010) Anisotropic features of the mechanical behaviour of Opalinus Clay. Proceedings of European rock mechanics symposium, Lausanne, Switzerland

30. Samper J, Yang C, Naves A, Yllera A, Hernández A, Molinero J, Soler JM, Hernán P, Mayor JC, Astudillo J (2006) A fully 3-D anisotropic numerical model of the DI-B in situ diffusion experiment in the Opalinus Clay formation. Phys Chem Earth 31(10-14):531-540

31. Schofield AN, Wroth CP (1968) Critical state soil mechanics. McGraw-Hill, New York

32. Schweiger HF, Wiltafsky C, Scharinger F, Galavi V (2009) A multilaminate framework for modelling induced and inherent anisotropy of soils. Géotechnique 59(2):87-101

33. Steiger R, Leung PK (1991) Consolidated undrained triaxial test procedure for shales. US symposium on rock mechanics, Paper, p 91-637

34. Steiger RP, Leung PK (1992) Quantitative determination of the mechanical properties of shales. SPE Drill Eng 7(3):181-185

35. Thury M (2002) The characteristics of the Opalinus Clay investigated in the Mont Terri underground rock laboratory in Switzerland. CR Phys 3(7-8):923-933

36. Van Loon L, Soler JM, Müller W, Bradbury MH (2004) Anisotropic diffusion in layered argillaceous rocks: a case study with Opalinus Clay. Environ Sci Technol 38(21):5721-5728

37. Voltolini M, Wenk HR, Mondol NH, Bjorlykke K, Jahren J (2009) Anisotropy of experimentally compressed kaolinite-illitequartz mixture. Geophysics 74(1):1-11

38. Wenk HR, Voltolini M, Mazurek M, Van Loon LR, Vinsot A (2008) Preferred orientations and anisotropy in shales: callovooxfordian shale (France) and Opalinus Clay (Switzerland). Clays Clay Miner 56(3):285-306 